\title{
What Factors Influence Non-Participation Most in Colorectal Cancer Screening? A Discrete Choice Experiment
}

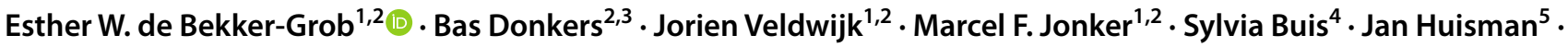 \\ Patrick Bindels ${ }^{6}$
}

Accepted: 21 October 2020 / Published online: 5 November 2020

(c) The Author(s) 2020

\begin{abstract}
Background and Objective Non-participation in colorectal cancer (CRC) screening needs to be decreased to achieve its full potential as a public health strategy. To facilitate successful implementation of CRC screening towards unscreened individuals, this study aimed to quantify the impact of screening and individual characteristics on non-participation in CRC screening. Methods An online discrete choice experiment partly based on qualitative research was used among 406 representatives of the Dutch general population aged 55-75 years. In the discrete choice experiment, respondents were offered a series of choices between CRC screening scenarios that differed on five characteristics: effectiveness of the faecal immunochemical screening test, risk of a false-negative outcome, test frequency, waiting time for faecal immunochemical screening test results and waiting time for a colonoscopy follow-up test. The discrete choice experiment data were analysed in a systematic manner using random-utility-maximisation choice processes with scale and/or preference heterogeneity (based on 15 individual characteristics) and/or random intercepts.

Results Screening characteristics proved to influence non-participation in CRC screening (21.7-28.0\% non-participation rate), but an individual's characteristics had an even higher impact on CRC screening non-participation (8.4-75.5\% nonparticipation rate); particularly the individual's attitude towards CRC screening followed by whether the individual had participated in a cancer screening programme before, the decision style of the individual and the educational level of the individual. Our findings provided a high degree of confidence in the internal-external validity.

Conclusions This study showed that although screening characteristics proved to influence non-participation in CRC screening, a respondent's characteristics had a much higher impact on CRC screening non-participation. Policy makers and physicians can use our study insights to improve and tailor their communication plans regarding (CRC) screening for unscreened individuals.
\end{abstract}

Esther W. de Bekker-Grob

debekker-grob@eshpm.eur.nl

1 Erasmus School of Health Policy \& Management, Erasmus University Rotterdam, P.O. Box 1738, 3000 DR Rotterdam, The Netherlands

2 Erasmus Choice Modelling Centre, Erasmus University, Rotterdam, The Netherlands

3 Erasmus School of Economics, Erasmus University, Rotterdam, The Netherlands

4 General Practice, Gezondheidscentrum Ommoord, Rotterdam, The Netherlands

5 General Practice, Het Doktershuis, Ridderkerk, The Netherlands

6 Department of General Practice, Erasmus MC-University Medical Centre Rotterdam, Rotterdam, The Netherlands

\section{Key Points for Decision Makers}

Although screening characteristics proved to influence non-participation in colorectal cancer screening, an individual's characteristics had a much higher impact on colorectal cancer screening non-participation.

Particularly, the individual's general attitude towards colorectal cancer screening and whether the individual had participated in a cancer screening programme before had a high impact on colorectal cancer screening nonparticipation.

Policy makers and physicians can use these insights to improve and tailor their communication plans regarding colorectal cancer screening for unscreened individuals. 


\section{Introduction}

Colorectal cancer (CRC) is one of the most common causes of cancer death in developed countries, with approximately 700,000 deaths worldwide in 2018 [1]. Population-based CRC screening is widely recommended as it can reduce the incidence and mortality of CRC [2-5]. There are several methods available for CRC screening, such as faecal testing (guaiac faecal occult blood testing, faecal immunochemical testing [FIT]) and endoscopic and radiologic screening tests (sigmoidoscopy, colonoscopy, computed tomography colonography) [6-11].

Participation is an important determinant of the effectiveness of CRC screening programmes. If screening is to achieve its full potential as a public health strategy, non-participation in screening needs to be decreased [12]. To facilitate participation in CRC screening programmes and tailored information directed towards unscreened individuals, a first important step is obtaining insights into determinants that drive non-participation and the trade-offs individuals are willing to make between participation and non-participation in population-based CRC screening. Non-participation is defined here as the condition of not being participating in population-based CRC screening. Knowing which determinants have a relatively high impact on non-participation will help policy makers and physicians to improve and tailor their communication plans efficiently regarding CRC screening.

The discrete choice experiment (DCE), a quantitative technique that is commonly used in healthcare research, is a useful method to obtain insights into determinants that have an impact on non-participation for medical interventions [13]. Although several DCE studies exist concerning preferences for population-based faecal screening [11, 14-20], none of them accounted for scale effects (i.e. how consistent individuals make their choices) and preference heterogeneity (i.e. to determine whether CRC screening non-participation depends on specific individual characteristics) simultaneously. This study provides a thorough analysis of the importance of such statistical model components. Our results reveal that accounting for both scale effects and preference heterogeneity is needed to obtain internal and external valid outcomes that are useful for health policy decisions and communication, which validates similar findings of de Bekker-Grob et al. [21] in the field of influenza vaccination. This study determined the influence of screening and individual characteristics on non-participation in CRC screening via a DCE while incorporating these important model components into the statistical analysis.

\section{Methods}

\subsection{Study Sample and Elicitation Mode}

An online sample of 400 individuals aged 55-75 years (i.e. target population for CRC screening) from the Dutch general population, nationally representative in terms of age, sex, education and geographic region was recruited via Survey Sampling International, a commercial survey sample provider. This number of individuals was calculated to be sufficiently large for reliable statistical analyses for our study [22]. Approval for the study was obtained from the Medical Ethics Committee, Erasmus MC (MEC-2016-095). All respondents gave their consent to participate in this study. The study was performed in accordance with the Declaration of Helsinki.

\subsection{Discrete Choice Experiment}

A DCE assumes that a given medical intervention, such as an CRC screening programme, can be described by its characteristics (e.g. screening effectiveness, screening interval, waiting time), and that the individual's preference for a medical intervention is determined by the levels of those characteristics (e.g. levels for screening interval: 'every year', 'every 2 years' or 'every 3 years') [23]. The relative importance of these characteristics can be assessed when individuals are forced to make trade-offs by offering a series of choices between medical intervention alternatives that have different combinations of levels [24] (see Fig. 1 for an example of such a 'choice task').

To develop and operationalise CRC screening characteristics with their levels for our DCE, we used a literature search (a snowball method was used) followed by interviews with experts in the field of CRC screening ( $n=4$ experts in the field of CRC screening to account for recent developments regarding FIT characteristics), and three focus groups with patients aged $55-75$ years $(n=21)$ recruited from and conducted in two general practices. After this qualitative work, the nominal group technique [25] was applied and used to select the most relevant CRC screening characteristics that may impact individuals' decisions to (non-)participate in CRC screening. That is, during the group interviews, participants (i.e. the same patients aged $55-75$ years $[n=21]$ from the focus groups recruited from two general practices) were asked to rank a number of potential attributes from most to least important. The mean group ranking of the attributes was then discussed in the group, after which participants could change their original individual ranking. The most relevant, and hence, selected characteristics were: effectiveness of the FIT, risk of a false-negative FIT outcome, frequency 
Fig. 1 Example of a colorectal cancer screening choice task
1. Effectiveness

2. Probability the screening test does not find the cancer

3. Waiting time for test results

4. Waiting time for followup test

5. Frequency of the screening

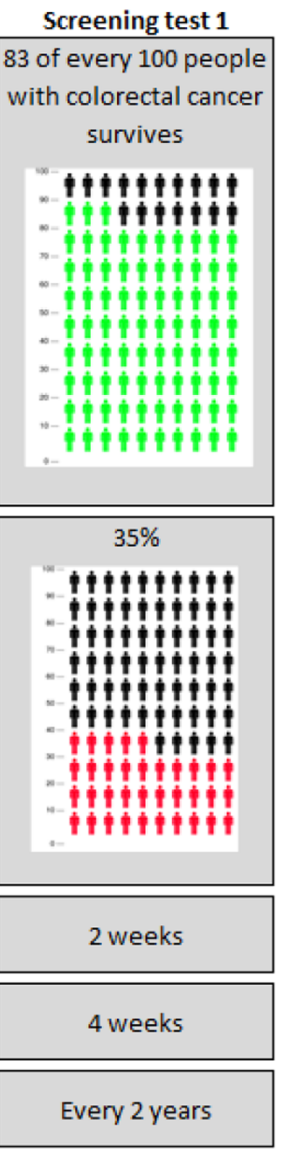

0

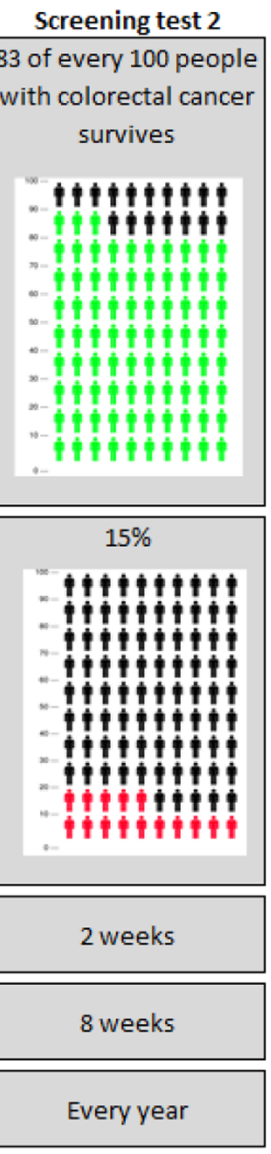

0
No screening

59 of every 100 people with colorectal cancer survives
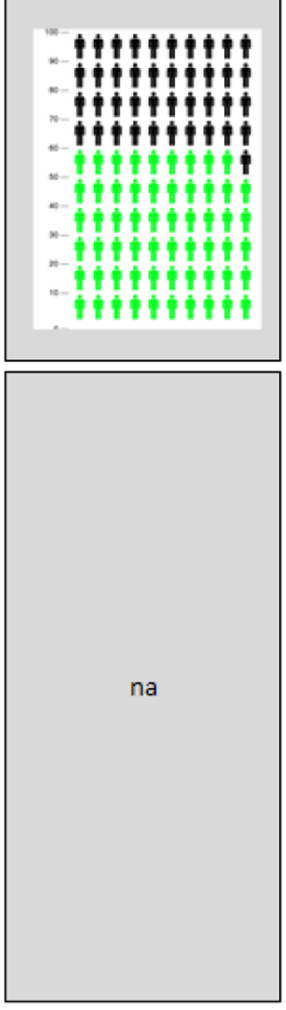

0

of the FIT, waiting time for FIT results and waiting time for a colonoscopy follow-up test. The levels for each of these screening characteristics incorporated the range of possible CRC screening outcomes (Table 1). These levels were based on the literature (see [26-28] for levels concerning test frequency, test efficiency and the risk of a false negative), current Dutch practice (i.e. waiting times to receive a FIT result and to undergo a colonoscopy) and expert opinion ( $n=4$ experts in the field of CRC screening to account for recent developments regarding FIT test characteristics). Noteworthy, in The Netherlands, FIT is used as biannual population-based CRC screening test, screening participants aged 55-75 years do not have to pay for CRC screening and the participation rate for population-based CRC screening is $72.7 \%$ (70.3\% and $75.1 \%$ participation rate for first and non-first invitees, respectively).

\subsection{Study Design and Questionnaire}

The combination of, in our case, five screening characteristics with three levels each (to test for non-linearity), resulted in almost 30,000 unique different pair-wise comparisons (i.e. choice tasks; combinations of two different CRC screening alternatives). As it is not feasible to present a single

individual with all combinations of these alternatives, a heterogeneous Bayesian efficient design was used that reduced the burden for respondents yet accommodated the reliable estimation of the preference parameters [29]. The prior preference information (attribute weights) as required for the Bayesian efficient optimisation approach was obtained from best guess priors using expert judgement and updated for this DCE study after a pilot run of 100 respondents. The overall DCE design comprised ten different sub-designs [30]. Each respondent was offered only one sub-design that contained 16 discrete choice tasks (Fig. 1). The 'opt out' alternative was included as CRC screening is a preventive intervention and, as in real life, respondents are not obliged to get screened for CRC. In each choice task, respondents were asked to choose the alternative that appealed most to them.

Apart from the 16 choice tasks, the questionnaire contained questions on 15 respondent characteristics: nine background variables (age, sex, educational level, household, having had cancer, CRC in family, general practice visit last month, hospital visit last month and health condition); three CRC screening-related variables (general attitude towards CRC screening [31], cancer screening experience and having had a positive cancer screening test result before); and three 
Table 1 Colorectal cancer (CRC) screening characteristics and its levels

\begin{tabular}{ll}
\hline Characteristics & Levels \\
\hline Effectiveness & $20 \%$ (i.e. 67 instead of 59 of every 100 people with CRC survives) \\
& $40 \%$ (i.e. 75 instead of 59 of every 100 people with CRC survives) \\
& $60 \%$ (i.e. 83 instead of 59 of every 100 people with CRC survives) \\
& $15 \%$ \\
Risk false negative (i.e. probability & \\
the screening test does not find the & \\
cancer) & $25 \%$ \\
& $35 \%$ \\
& 1 week \\
Waiting time for test results & 2 weeks \\
& 3 weeks \\
& 2 weeks \\
Waiting time for follow-up test & 4 weeks \\
& 8 weeks \\
Frequency of the screening & Every year \\
& Every 2 years \\
& Every 3 years
\end{tabular}

decision-making skills variables (decision style [32], health literacy $[33,34]$ and numeracy $[35,36])$. The latter is important as decisions made by respondents are widely recognised as being affected by individual differences, and previous research showed that accounting for decision style, health literacy, and numeracy is important to guarantee internal and external valid DCE outcomes [21, 37]. These 15 individual characteristics were of interest based on the literature [21, 37], expert opinions and focus groups (see Sect. 2.2) and hypothesised to have an impact on CRC screening (non-) participation. The questionnaire also contained a question that assessed the perceived difficulty of the questionnaire (5-point scale). The questionnaire was pilot tested $(n=20$; the patients used for this pre-pilot study were another 20 to the focus groups [i.e. no overlap]) to check for any problems in interpretation and face validity. It was a qualitative prepilot by using a think-aloud strategy to test whether patients understood the questionnaire and interpreted the attributes and levels in a manner we wanted them to. As none of the respondents raised any problems, no alterations were made.

\subsection{Statistical Analyses}

Several models exist to analyse discrete choice data [13, 38, 39]. Each choice model has its set of features, which should fit the intentions of the research and match the respondents' choice behavior. Given our interest in accounting for systematic preference heterogeneity (i.e. to determine whether CRC screening non-participation depends on specific individual characteristics), while also taking scale effects (i.e. how consistent respondents make their choices), our sample size and the model fit into account, led to the decision to employ a heteroscedastic model in error component using Pythonbiogeme software [40]. We used a four-step approach to determine the optimal utility function (see Table 2). The final model was based on backward selection, Bayesian Information Criterion, and accuracy in prediction of CRC screening choices on an aggregate and individual level.

First, we tested several different specifications for the utility function (i.e. categorical/numerical screening characteristic levels, two-way interactions between screening characteristics, several screening characteristic transformations) [Model A; multinomial logit model]. Second, we tested several scale components to the utility function (Model B; heteroscedastic multinomial logit model). Third, we allowed for several covariates (15 individual characteristics) to enter the utility function (Model C; heteroscedastic multinomial logit model plus systematic preference heterogeneity). Finally, a random intercept was added to the utility function (Model D; same model as Model $\mathrm{C}$ but using a random intercept). The random intercept (alternative specific constant; ASC) took account of whether respondents systematically viewed the CRC screening alternative(s) differently from the no CRC screening alternative. Noteworthy, using the coefficients of Model D, the software Pythonbiogeme [40], the conditional parameter approach of Train [41] and Revelt \& Train [42], and Excel [43], we were able to determine the ASCs per individual (ASC_i; hence $\hat{\alpha}_{n}$ ).

For the parameter estimates (coefficients), the statistical significance $(p \leq 0.05)$ indicates whether respondents considered the characteristic(level) important in their decision to participate or not in CRC screening. The sign of the coefficient reflects whether the characteristic has a positive or negative effect on utility for CRC screening. In terms 
Table 2 Four-step approach to systematic analyse the discrete choice experiment datas

\begin{tabular}{llllll}
\hline Step & \multicolumn{3}{l}{ Model } & & \\
\cline { 2 - 6 } & A & B & C & D \\
\hline 1. Random utility maximization decision rule & $\times$ & $\times$ & $\times$ & $\times$ \\
2. Systematic scale heterogeneity & & $\times$ & $\times$ & $\times$ \\
3. Systematic preference heterogeneity & & & $\times$ & $\times$ \\
4. Random opt-out (i.e. no CRC screening) utility & & & & & $\times$ \\
\hline
\end{tabular}

$C R C$ colorectal cancer

of the scale parameters, statistically significant parameter estimates indicate that the associated covariate changes the scale of the utility component relative to the unobserved random component of utility. When a covariate has a positive (negative) coefficient, this increases (decreases) the scale of utility, which results in more (less) consistent choices. The benefit of such scale effects is that it allows some patients to have very clear and well-established preferences, while for others the comparisons and choice might be more difficult and hence noisier [44, 45].

\subsection{Expected Non-Participation in Colorectal Cancer Screening}

Choice probabilities (i.e. the expected CRC screening nonparticipation) were calculated to provide a method to convey DCE results in a more meaningful manner for policy makers and physicians. We calculated the choice probability for a base-case CRC screening and a base-case individual by taking the exponent of the total utility for CRC screening divided by the exponent of utility of both CRC screening and no CRC screening. The base-case CRC screening programme was chosen to resemble a common Dutch practice situation, and included the following attribute levels: a CRC screening programme that has an effectiveness of $40 \%$ (i.e. 75 instead of 59 of every 100 persons with CRC survives), a $25 \%$ risk of a false-negative outcome, a screening frequency of every 2 years, a 2-week waiting time for FIT results, and a 4-week waiting time for a colonoscopy follow-up test.

As there was no clear rationale to choose a specific basecase individual, we decided to opt for a base-case individual that had all dummy-coded ' 1 ' characteristics: 'a low educated male individual aged 55-64 years with a positive attitude for CRC screening, who has not had cancer. He has good health literacy and numeracy skills and a non-deliberative decision style, has screening experience, but did not experience a bad screening test result yet. He does not have CRC diagnosed in his family, has a good health condition, did not visit the general practitioner or hospital in the last month, and is living together with a partner or family member'. To investigate the impact of changing a screening or an individual characteristic on CRC screening non-participation, univariate estimates (i.e. one-way impact) for predicted probability of CRC screening non-participation were calculated. Here, we used the same approach as described in de Bekker-Grob et al. [21].

\section{Results}

\subsection{Respondents}

From the total of 485 panel members aged 55-75 years who started the survey, $406(83.7 \%)$ completed the questionnaire, resulting in 79 dropouts $(16.3 \%)$. Less than $10 \%$ of respondents that completed the survey perceived filling out the questionnaire as difficult. Respondents had a mean age of 63.3 years (standard deviation $=5.4$ ), 201 respondents $(49.5 \%)$ were male and one-third had a lower educational level (Table 3).

About $74 \%$ of the respondents reported that they were in good health, 54 respondents (13.3\%) had cancer and 298 respondents $(73.4 \%)$ mentioned that they have experience with cancer screening (Table 3). Ninety-three percent of the respondents $(N=298)$ stated that they would participate in $\mathrm{CRC}$ screening if received an invitation.

\subsection{Discrete Choice Experiment Results}

The DCE results can be found in Table 4. The main message of Table 4 is that (i) all screening characteristics proved to be important in the decision to opt in or out for CRC screening; (ii) the DCE results showed a high level of validity; and (iii) preference heterogeneity among respondents from systematic sources was found to be substantial. The heteroscedastic multinomial logit model, which included respondent characteristics as well as a random intercept, resulted in the best model fit and prediction accuracy (see Model D, Table 4).

Focusing in more detail on Model D, all screening characteristics proved to be important in the decision to opt in or out for CRC screening $(p<0.01)$. The screening characteristics had the expected sign and order, and showed, therefore, theoretical validity. In other words, there was a higher probability to participate in CRC screening, if the CRC screening was more effective, had a smaller risk of false-negative outcomes and had a shorter waiting time for the colonoscopy follow-up test.

As a validity check, the predicted CRC screening participation of $90.6 \%$ (confidence interval $87.4-93.3 \%$ ) at an aggregate level was in line with the observed CRC screening participation intention of $92.9 \%$ (i.e. what respondents stated they will do; see previous paragraph) (Table 4). That is, the observed CRC screening participation on the group level was correctly predicted by our DCE. Additionally, this 
Table 3 Respondents' characteristics

\begin{tabular}{|c|c|c|}
\hline & $N=406$ & $\%$ \\
\hline Male & 201 & 49.5 \\
\hline Age (mean; SD) & 63.3 & 5.4 \\
\hline Aged $<65$ years & 234 & 57.6 \\
\hline Aged 65 years or older & 172 & 42.4 \\
\hline \multicolumn{3}{|l|}{ Education } \\
\hline Low & 125 & 30.8 \\
\hline Medium & 162 & 39.9 \\
\hline High & 118 & 29.1 \\
\hline \multicolumn{3}{|l|}{ Health } \\
\hline Good & 302 & 74.4 \\
\hline Moderate & 91 & 22.4 \\
\hline Bad & 13 & 3.2 \\
\hline \multicolumn{3}{|l|}{ Household } \\
\hline Living alone & 135 & 33.3 \\
\hline Living together (with partner and/or children) & 271 & 66.7 \\
\hline Visited GP last month (yes) & 141 & 34.7 \\
\hline Visited hospital last month (yes) & 97 & 23.9 \\
\hline Suffered from cancer (yes) & 54 & 13.3 \\
\hline CRC history family member (yes) & 93 & 22.9 \\
\hline Have experience with screening (yes) & 298 & 73.4 \\
\hline CRC screening test asked for further research (yes) & 10 & 2.5 \\
\hline Family or friends impact CRC screening decision (yes) & 21 & 5.2 \\
\hline Say that s/he will opt for CRC screening (fixed choice; yes) & 377 & 92.9 \\
\hline \multicolumn{3}{|l|}{ General attitude CRC screening } \\
\hline In favour & 357 & 87.9 \\
\hline Neutral & 44 & 10.8 \\
\hline Against & 5 & 1.2 \\
\hline \multicolumn{3}{|l|}{ Health literacy } \\
\hline Average (mean; SD) & 2.9 & 0.5 \\
\hline Good health literacy (scored 3 or higher) & 177 & 43.6 \\
\hline \multicolumn{3}{|l|}{ Numeracy } \\
\hline SNS average (mean; SD) & 4.1 & 1.0 \\
\hline Objective scores correct (yes) & 271 & 66.7 \\
\hline Good numeracy (i.e. 4 or higher SNS + obj scores correct [yes]) & 257 & 63.3 \\
\hline \multicolumn{3}{|l|}{ Decision style } \\
\hline Decision style average (mean; SD) & 3.0 & 0.5 \\
\hline Rather deliberative $(>3)$ & 138 & 34.0 \\
\hline Neutral (3) & 120 & 29.6 \\
\hline Rather intuitive $(<3)$ & 148 & 36.5 \\
\hline
\end{tabular}

$C R C$ colorectal cancer, GP general practitioner, obj objective, SD standard deviation, SNS Subjective Numeracy Scale

model also almost perfectly predicted the observed CRC screening participation on the respondent level (97.1\% out of $100 \%$ ). Hence, the DCE results showed a high level of validity.

Preference heterogeneity among respondents from systematic sources was found to be substantial (Table 4). All 15 respondent characteristics had an impact on one or more screening characteristic levels, and hence directly on nonparticipation in CRC screening (see next paragraph).

\subsection{Impact Characteristics on Non-Participation in Colorectal Cancer Screening}

Screening characteristics and respondents' characteristics both influenced non-participation in CRC screening. 
Table 4 Discrete choice experiment result

\begin{tabular}{|c|c|c|c|c|c|c|c|c|}
\hline \multirow[t]{3}{*}{ Utility function } & \multirow{2}{*}{\multicolumn{2}{|c|}{$\frac{\text { Model A }}{\text { Model MNL model }}$}} & \multirow{2}{*}{\multicolumn{2}{|c|}{$\frac{\text { Model B }}{\text { HMNL model }}$}} & \multirow{2}{*}{\multicolumn{2}{|c|}{$\begin{array}{l}\text { Model C } \\
\text { HMNL model }+ \\
\text { systematic preference } \\
\text { heterogeneity }\end{array}$}} & \multirow{2}{*}{\multicolumn{2}{|c|}{$\begin{array}{l}\text { Model D } \\
\text { HMNL model }+ \\
\text { systematic preference } \\
\text { heterogeneity + random } \\
\text { opt-out utility }\end{array}$}} \\
\hline & & & & & & & & \\
\hline & Coeff value & $p$ value & Coeff value & $p$ value & Coeff value & $p$ value & Coeff value & $p$ value \\
\hline \multicolumn{9}{|l|}{ Alternative-specific constant } \\
\hline No CRC screening & -2.710 & $<0.01 * * *$ & -2.620 & $<0.01 * * *$ & 0.517 & 0.23 & -0.407 & 0.91 \\
\hline \multicolumn{9}{|l|}{ Attributes (main effects) } \\
\hline Scaled (/10) effectiveness & 0.020 & $<0.01 * * *$ & 0.018 & $<0.01 * * *$ & 0.008 & 0.20 & 0.016 & 0.04 \\
\hline False negative & -0.048 & $<0.01 * * *$ & -0.052 & $<0.01 * * *$ & 0.001 & 0.94 & -0.022 & 0.15 \\
\hline \multicolumn{9}{|l|}{ Frequency } \\
\hline Every year & 0.133 & & 0.127 & & -0.132 & & -0.176 & \\
\hline Every 2 years & 0.144 & $0.02 * *$ & 0.214 & $<0.01 * * *$ & 0.335 & $<0.01 * * *$ & 0.342 & $<0.01 * * *$ \\
\hline Every 3 years & -0.277 & $<0.01 * * *$ & -0.341 & $<0.01 * * *$ & -0.203 & $0.09 *$ & -0.166 & 0.18 \\
\hline \multicolumn{9}{|l|}{ Waiting time diagn test } \\
\hline 1 week & -0.033 & & -0.180 & & -0.116 & & -0.096 & \\
\hline 2 weeks & 0.034 & 0.58 & 0.241 & $<0.01 * * *$ & 0.174 & $0.01 * * *$ & 0.194 & $<0.01 * * *$ \\
\hline 3 weeks & -0.001 & 0.99 & -0.061 & $<0.01 * * *$ & -0.058 & 0.40 & -0.099 & 0.15 \\
\hline \multicolumn{9}{|l|}{ Waiting time f-up test } \\
\hline 2 weeks & -0.091 & & 0.131 & & 0.239 & & 0.218 & \\
\hline 4 weeks & 0.119 & $0.06^{*}$ & 0.036 & 0.40 & 0.019 & 0.74 & 0.048 & 0.36 \\
\hline 8 weeks & -0.028 & 0.66 & -0.167 & $<0.01 * * *$ & -0.258 & $<0.01 * * *$ & -0.265 & $<0.01 * * *$ \\
\hline \multicolumn{9}{|l|}{ Two-way interactions } \\
\hline \multicolumn{9}{|l|}{ Scaled (/10) } \\
\hline Eff $\times$ fneg & 0.001 & 0.64 & 0.001 & 0.55 & 0.001 & 0.51 & 0.002 & 0.18 \\
\hline \multicolumn{9}{|l|}{ Scaled (/10) } \\
\hline Eff $\times$ freq 2 & 0.008 & 0.59 & -0.021 & $0.03 * *$ & -0.032 & $0.01 * * *$ & -0.032 & $0.01 * * *$ \\
\hline \multicolumn{9}{|l|}{ Scaled $(/ 10)$} \\
\hline Eff $\times$ freq 3 & -0.019 & 0.23 & 0.026 & $0.01 * * *$ & 0.047 & $<0.01 * * *$ & 0.049 & $<0.01 * * *$ \\
\hline \multicolumn{9}{|l|}{ Scaled (/100) } \\
\hline Eff $\times$ waitdiag2 & 0.003 & 0.85 & -0.009 & 0.35 & -0.009 & 0.43 & -0.012 & 0.26 \\
\hline \multicolumn{9}{|l|}{ Scaled $(/ 100)$} \\
\hline Eff $\times$ waitdiag 3 & 0.004 & 0.80 & 0.018 & $0.08^{*}$ & 0.015 & 0.22 & 0.020 & $0.08 *$ \\
\hline \multicolumn{9}{|l|}{ Scaled (/10) } \\
\hline Eff $\times$ waitfup4 & -0.185 & 0.22 & -0.017 & 0.86 & 0.062 & 0.60 & 0.005 & 0.97 \\
\hline \multicolumn{9}{|l|}{ Scaled $(/ 10)$} \\
\hline Eff $\times$ waitfup 8 & -0.281 & $0.05 * *$ & 0.085 & 0.37 & 0.054 & 0.64 & 0.083 & 0.44 \\
\hline \multicolumn{9}{|l|}{ Scale heterogeneity } \\
\hline Age $>65$ year & - & & -0.356 & $<0.01 * * *$ & 0.633 & $<0.01 * * *$ & 0.743 & 0.11 \\
\hline Did not have (had) cancer & - & & 0.285 & $<0.01 * * *$ & -0.090 & $<0.01 * * *$ & -0.122 & 0.31 \\
\hline Rather deliberative decision-making & - & & 0.403 & $<0.01 * * *$ & 0.493 & $<0.01 * * *$ & 0.352 & $<0.01 * * *$ \\
\hline Bad experience & - & & -2.410 & $<0.01 * * *$ & -0.333 & $0.09 *$ & -0.541 & 0.17 \\
\hline Health literacy & - & & -0.246 & $<0.01 * * *$ & 0.104 & $0.09 *$ & 0.059 & 0.51 \\
\hline Living alone & - & & 0.337 & $<0.01 * * *$ & 0.562 & $<0.01 * * *$ & 0.540 & $<0.01 * * *$ \\
\hline Male & - & & 0.253 & $<0.01 * * *$ & -0.456 & $<0.01 * * *$ & -0.213 & 0.04 \\
\hline Good nummeracy & - & & 0.279 & $<0.01 * * *$ & -0.575 & $<0.01 * * *$ & -0.350 & $<0.01 * * *$ \\
\hline Did not have screening experience & - & & -1.490 & $<0.01 * * *$ & -0.128 & $0.07 *$ & -0.132 & 0.22 \\
\hline \multicolumn{9}{|l|}{ Systematic preference heterogeneity } \\
\hline $\begin{array}{l}\text { Age }>65 \text { year } \times \text { constant 'no screen- } \\
\text { ing' }\end{array}$ & - & & - & & 1.730 & $<0.01 * * *$ & 1.690 & 0.40 \\
\hline
\end{tabular}


Table 4 (continued)

\begin{tabular}{|c|c|c|c|c|c|c|}
\hline \multirow[t]{3}{*}{ Utility function } & \multirow{2}{*}{$\frac{\text { Model A }}{\text { Model MNL model }}$} & \multirow{2}{*}{$\frac{\text { Model B }}{\text { HMNL model }}$} & \multirow{2}{*}{\multicolumn{2}{|c|}{$\begin{array}{l}\text { Model C } \\
\text { HMNL model }+ \\
\text { systematic preference } \\
\text { heterogeneity }\end{array}$}} & \multirow{2}{*}{\multicolumn{2}{|c|}{$\begin{array}{l}\text { Model D } \\
\text { HMNL model + } \\
\text { systematic preference } \\
\text { heterogeneity + random } \\
\text { opt-out utility }\end{array}$}} \\
\hline & & & & & & \\
\hline & Coeff value $p$ value & Coeff value $p$ value & Coeff value & $p$ value & Coeff value & $p$ value \\
\hline Age $>65$ year $\times$ eff & - & - & -0.021 & $<0.01 * * *$ & -0.026 & $<0.01 * * *$ \\
\hline Age $>65$ year $\times$ fneg & - & - & 0.033 & $<0.01 * * *$ & 0.040 & $<0.01 * * *$ \\
\hline Age $>65$ year $\times$ freq 2 & - & - & -0.111 & $0.02 * *$ & -0.132 & $0.01 * * *$ \\
\hline Age $>65$ year $\times$ freq 3 & - & - & 0.149 & $0.01 * * *$ & 0.165 & $0.01 * * *$ \\
\hline Age $>65$ year $\times$ waitdiagn 2 & - & - & -0.033 & 0.44 & -0.051 & 0.22 \\
\hline Age $>65$ year $\times$ waitdiagn 3 & - & - & -0.130 & $0.01 * * *$ & -0.100 & $0.04 * *$ \\
\hline Attitude for $\times$ constant 'no screening' & - & - & -3.760 & $<0.01 * * *$ & -15.500 & $<0.01 * * *$ \\
\hline Attitude for $\times$ eff & - & - & 0.020 & $<0.01 * * *$ & 0.014 & $0.02 * *$ \\
\hline Attitude for $\times$ fneg & - & - & -0.047 & $<0.01 * * *$ & -0.035 & $<0.01 * * *$ \\
\hline Attitude for $\times$ freq 2 & - & - & 0.067 & 0.43 & 0.065 & 0.44 \\
\hline Attitude for $\times$ freq 3 & - & - & -0.449 & $<0.01 * * *$ & -0.503 & $<0.01 * * *$ \\
\hline No cancer $\times$ constant 'no screening' & - & - & -1.060 & $<0.01 * * *$ & -4.740 & $0.07 *$ \\
\hline No cancer $\times$ fneg & - & - & -0.011 & $0.10 *$ & -0.009 & 0.16 \\
\hline Crc in family $\times$ eff & - & - & -0.005 & $0.09 *$ & -0.007 & $0.06^{*}$ \\
\hline Crc in family $\times$ fneg & - & - & 0.021 & $<0.01 * * *$ & 0.020 & $<0.01 * * *$ \\
\hline Crc in family $\times$ waitdiagn 2 & - & - & -0.081 & $0.06 *$ & -0.074 & $0.08 *$ \\
\hline Crc in family $\times$ waitdiagn 3 & - & - & 0.092 & $0.05 * *$ & 0.078 & $0.10^{*}$ \\
\hline $\begin{array}{l}\text { Deliberative DM style } \times \text { constant 'no } \\
\text { screening' }\end{array}$ & - & - & -0.408 & $0.07 *$ & -4.910 & $0.05^{* *}$ \\
\hline Deliberative DM style $\times$ fneg & - & - & -0.013 & $0.02 * *$ & -0.015 & $0.02 * *$ \\
\hline Deliberative DM style $\times$ freq2 & - & - & -0.076 & $0.08 *$ & -0.075 & $0.07 *$ \\
\hline Deliberative DM style $\times$ freq3 & - & - & 0.080 & $0.09 *$ & 0.085 & $0.07 *$ \\
\hline $\begin{array}{l}\text { High education } \times \text { constant 'no screen- } \\
\text { ing' }\end{array}$ & - & - & -0.859 & $<0.01 * * *$ & -2.990 & 0.19 \\
\hline High education $\times$ fneg & - & - & -0.011 & $0.04 * *$ & -0.012 & $0.02 * *$ \\
\hline Bad experience $\times$ fneg & - & - & -0.032 & $<0.01 * * *$ & -0.036 & 0.30 \\
\hline Bad experience $\times$ freq 2 & - & - & 0.366 & $0.04 * *$ & 0.539 & $0.09 *$ \\
\hline Bad experience $\times$ freq 3 & - & - & -0.255 & 0.17 & -0.179 & 0.48 \\
\hline Last month GP visit $\times$ eff & - & - & -0.008 & $0.01 * * *$ & -0.009 & $0.01 * * *$ \\
\hline Last month GP visit $\times$ fneg & - & - & 0.015 & $<0.01 * * *$ & 0.014 & $0.02 * *$ \\
\hline Last month GP visit $\times$ freq 2 & - & - & 0.007 & 0.87 & 0.015 & 0.71 \\
\hline Last month GP visit $\times$ freq 3 & - & - & -0.136 & $0.01 * * *$ & -0.123 & $0.01 * * *$ \\
\hline Last month GP visit $\times$ waitdiagn 2 & - & - & -0.100 & $0.01 * * *$ & -0.086 & $0.03 * *$ \\
\hline Last month GP visit $\times$ waitdiagn 3 & - & - & 0.064 & 0.14 & 0.056 & 0.18 \\
\hline Good health $\times$ constant 'no screening' & - & - & -0.636 & $<0.01 * * *$ & 0.144 & 0.95 \\
\hline Good health $\times$ fneg & - & - & -0.011 & $0.06^{*}$ & -0.009 & 0.11 \\
\hline Good health $\times$ freq 2 & - & - & 0.086 & $0.07 *$ & 0.090 & $0.05 * *$ \\
\hline Good health $\times$ freq 3 & - & - & -0.061 & 0.24 & -0.060 & 0.22 \\
\hline $\begin{array}{l}\text { Good health literacy } \times \text { constant 'no } \\
\text { screening' }\end{array}$ & - & - & 0.628 & $<0.01 * * *$ & 0.677 & 0.73 \\
\hline Good health literacy $\times$ fneg & - & - & 0.012 & $0.02 * *$ & 0.011 & $0.05 * *$ \\
\hline Good health literacy $\times$ freq 2 & - & - & -0.103 & $0.02 * *$ & -0.091 & $0.02 * *$ \\
\hline Good health literacy $\times$ freq 3 & - & - & 0.057 & 0.22 & 0.066 & 0.13 \\
\hline Last month hospital visit $\times$ eff & - & - & 0.005 & $0.08 * *$ & 0.002 & 0.44 \\
\hline Living alone $\times$ constant 'no screening' & - & - & 0.924 & $<0.01 * * *$ & 1.110 & 0.58 \\
\hline
\end{tabular}


Table 4 (continued)

\begin{tabular}{|c|c|c|c|c|c|c|}
\hline \multirow[t]{3}{*}{ Utility function } & \multirow{2}{*}{$\frac{\text { Model A }}{\text { Model MNL model }}$} & \multirow{2}{*}{$\frac{\text { Model B }}{\text { HMNL model }}$} & \multirow{2}{*}{\multicolumn{2}{|c|}{$\begin{array}{l}\text { Model C } \\
\text { HMNL model }+ \\
\text { systematic preference } \\
\text { heterogeneity }\end{array}$}} & \multirow{2}{*}{\multicolumn{2}{|c|}{$\begin{array}{l}\text { Model D } \\
\text { HMNL model + } \\
\text { systematic preference } \\
\text { heterogeneity + random } \\
\text { opt-out utility }\end{array}$}} \\
\hline & & & & & & \\
\hline & Coeff value $p$ value & Coeff value $p$ value & Coeff value & $p$ value & Coeff value & $p$ value \\
\hline Living alone $\times$ freq 2 & - & - & -0.064 & 0.14 & -0.073 & $0.07 *$ \\
\hline Living alone $\times$ freq 3 & - & - & 0.230 & $<0.01 * * *$ & 0.206 & $<0.01 * * *$ \\
\hline Living alone $\times$ wait f-up4 & - & - & -0.037 & 0.34 & -0.047 & 0.19 \\
\hline Living alone $\times$ wait $\mathrm{f}$-up8 & - & - & 0.076 & $0.05 * *$ & 0.080 & $0.03 * *$ \\
\hline Male $\times$ constant ' no screening' & - & - & -1.300 & $<0.01 * * *$ & -1.360 & 0.53 \\
\hline Male $\times$ fneg & - & - & -0.013 & $0.06^{*}$ & -0.006 & 0.33 \\
\hline Male $\times$ freq 2 & - & - & 0.100 & $0.08^{*}$ & 0.073 & 0.13 \\
\hline Male $\times$ freq 3 & - & - & -0.224 & $<0.01 * * *$ & -0.151 & $0.02 * *$ \\
\hline Male $\times$ wait diagn 2 & - & - & 0.014 & 0.78 & -0.010 & 0.79 \\
\hline Male $\times$ wait diagn 3 & - & - & 0.107 & $0.04 * *$ & 0.057 & 0.17 \\
\hline $\begin{array}{l}\text { Good numeracy } \times \text { constant 'no screen- } \\
\text { ing' }\end{array}$ & - & - & -1.720 & $<0.01 * * *$ & -0.030 & 0.99 \\
\hline Good numeracy $\times$ eff & - & - & 0.028 & $<0.01 * * *$ & 0.024 & $<0.01 * * *$ \\
\hline Good numeracy $\times$ fneg & - & - & -0.064 & $<0.01 * * *$ & -0.052 & $<0.01 * * *$ \\
\hline $\begin{array}{l}\text { Screening experience } \times \text { constant ' no } \\
\text { screening' }\end{array}$ & - & - & 1.990 & $<0.01 * * *$ & 7.180 & $0.01 * * *$ \\
\hline No screening experience $\times$ freq 2 & - & - & -0.119 & $0.08 *$ & -0.123 & $0.06^{*}$ \\
\hline No screening experience $\times$ freq 3 & - & - & -0.031 & 0.66 & -0.056 & 0.43 \\
\hline No screening experience $\times$ wait f-up 4 & - & - & -0.017 & 0.76 & -0.001 & 0.99 \\
\hline No screening experience $\times$ wait $f$-up 8 & - & - & 0.236 & $<0.01 * * *$ & 0.184 & $<0.01 * * *$ \\
\hline Random opt-out utility (s.d. of ASC) & - & - & - & & 10.200 & $<0.01 * * *$ \\
\hline \multicolumn{7}{|l|}{ Goodness-of-fit } \\
\hline LL & -5614 & -5265 & -4778 & & -4084 & \\
\hline Number Free Param. & 16 & 25 & 86 & & 87 & \\
\hline AIC & 1.734 & 1.629 & 1.497 & & 1.284 & \\
\hline $\mathrm{BIC}$ & 1.743 & 1.644 & 1.551 & & 1.338 & \\
\hline Respondents & 406 & 406 & 406 & & 406 & \\
\hline \multicolumn{7}{|l|}{ CRC screening uptake } \\
\hline Observed & $92.9 \%$ & $92.9 \%$ & $92.9 \%$ & & $92.9 \%$ & \\
\hline \multicolumn{7}{|l|}{ Predicted } \\
\hline Mean & $84.9 \%$ & $86.5 \%$ & $88.0 \%$ & & $90.6 \%$ & \\
\hline Delta & $-8.0 \%$ & $-6.4 \%$ & $-4.9 \%$ & & $-2.3 \%$ & \\
\hline Lower bound CI & $81.1 \%$ & $82.7 \%$ & $84.4 \%$ & & $87.4 \%$ & \\
\hline Upper bound CI & $88.3 \%$ & $89.6 \%$ & $90.9 \%$ & & $93.3 \%$ & \\
\hline $\begin{array}{l}\text { Proportion of choices that were predicted } \\
\text { correctly at an individual level }\end{array}$ & $79.9 \%$ & $83.0 \%$ & $87.9 \%$ & & $97.1 \%$ & \\
\hline
\end{tabular}

AIC Akaike Information Criterion, ASC alternative specific constant, ascn alternative specific constant opt-out alternative, BIC Bayesian Information Criterion, $C I$ confidence interval, coeff coefficient, $C R C$ colorectal cancer, diagn diagnostic, DM decision making, eff effectiveness, fneg false negative, freq frequency, $f$-up follow-up, $G P$ general practitioner, $H M N L$ heteroscedastic multinomial $\operatorname{logit}, L L \log$-likelihood, $M N L$ multinomial logit, s.d. standard deviation, * $p<0.10 ; * * p<0.05 ; * * *<0.01$

Assuming a base-case respondent and a realistic CRC screening scenario, the probability to opt for CRC screening was $75.3 \%$, which corresponds to a non-participation rate of $24.7 \%$. One-way changes in screening characteristics and respondents' characteristics changed this non-participation rate from $21.7 \%$ up to $28.0 \%$ (Fig. 2) and from $8.4 \%$ up to $75.5 \%$ (Fig. 3), respectively. 
From the screening characteristics, the risk of a falsenegative FIT outcome had the strongest impact on the nonparticipation rate in CRC screening (Fig. 2). However, a respondent's characteristics had an even stronger impact on non-participation. The strongest impact on non-participation was the respondent's general attitude towards CRC screening followed by whether the respondent had participated in a cancer screening programme before, the decision style of the respondent and the educational level of the respondent (Fig. 3).

\section{Discussion}

There are just a handful of DCE studies investigating preferences for CRC screening (although none of them focused on how screening and individuals' characteristics impact on CRC screening non-participation) [11, 14-20]. Several of these DCE studies found that risk reduction of CRC-related mortality is an important screening characteristic for the individual to prefer CRC screening over no screening [11, $14,17]$, which is in line with our findings. Our finding that the screening interval has an influence on preferences for CRC screening was also found by Hol et al. [11], and van Dam et al. [17]. Benning et al. [14] investigated whether several sociodemographic variables impacted participants' preferences for CRC screening. They found that being younger, higher educated, experienced with cancer screening and female positively impacted CRC screening participation. Apart from sex, these results are in-line with our findings. Interestingly, in our DCE study with the heteroscedastic multinomial logit model specification, we found that having a more deliberative decision style resulted in higher choice consistency. This result was also found in a DCE study of de Bekker-Grob et al. [21] concerning external validity of DCE outcomes, which raises the question whether the decision style should be measured and taken into account into future health-related DCE studies.

Our study showed that if the individual had a negative attitude towards CRC screening and/or if the individual had not opted for a cancer screening programme before, this individual would be less likely to participate in CRC screening. Hence, to reduce CRC screening non-participation substantially, tackling the negative attitude of individuals

\section{CRC screening non-participation (\%)}

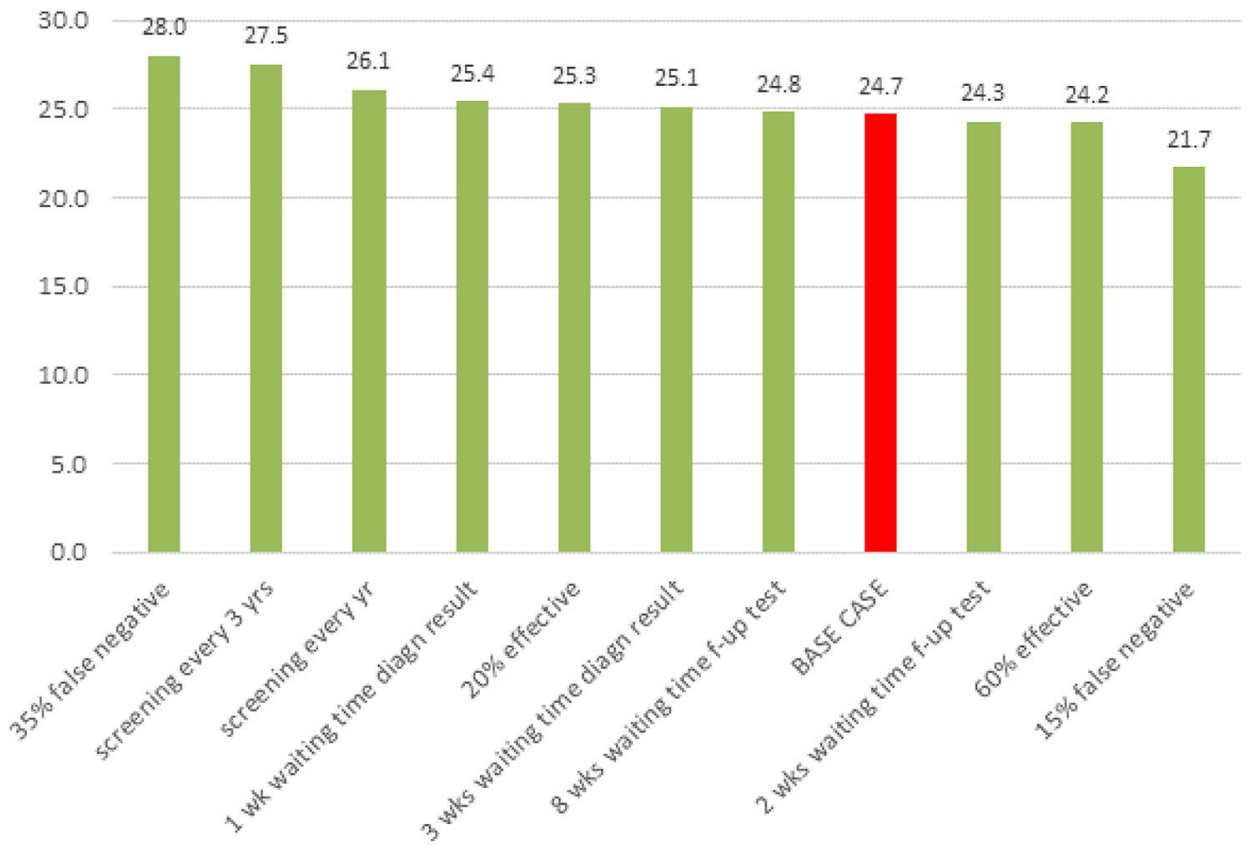

Fig. 2 One-way impact of screening characteristics on non-participation in colorectal cancer (CRC) screening. Note: The base case is a 'low educated male individual aged 55-64 years with a positive attitude for CRC screening, who has not had cancer. He has good health literacy and numeracy skills and a non-deliberative decision style, has screening experience, but has not experienced a bad screening test result yet. He does not have CRC diagnosed in his family, has a good health condition, did not visit the general practitioner (GP) or hospital in the last month, and is living together with a partner or family member. He is invited to join a CRC screening programme that has an effectiveness of $40 \%$, has a $25 \%$ risk of a false-negative outcome, a screening frequency of every 2 years, a 2-week waiting time for faecal immunochemical testing results and a 4-week waiting time for a colonoscopy follow-up (f-up) test.' diagn diagnostic 


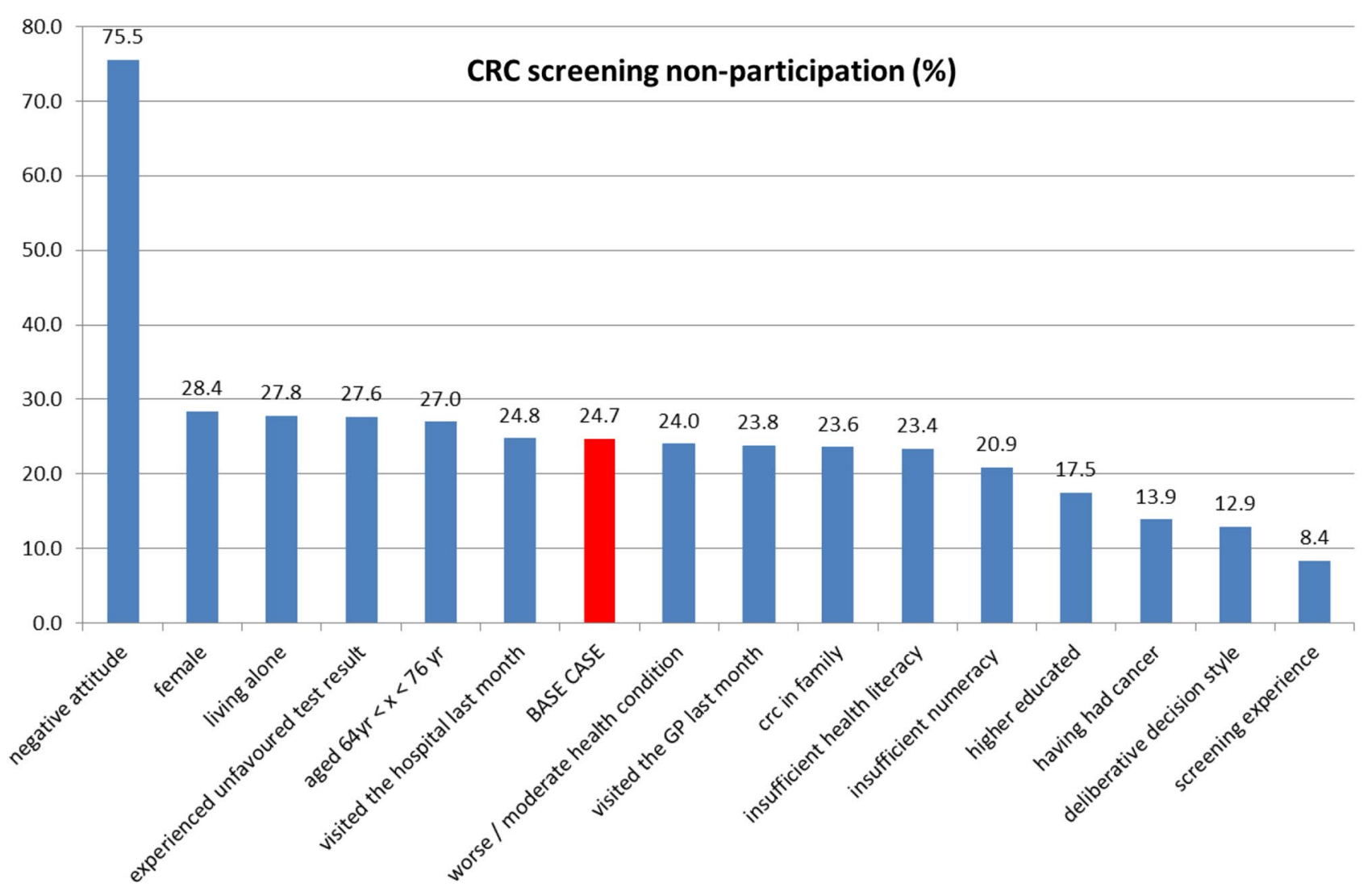

Fig. 3 One-way impact of respondent characteristics on non-participation in colorectal cancer (CRC) screening. Note: The base case is a 'low educated male individual aged 55-64 years with a positive attitude for CRC screening, who has not had cancer. He has good health literacy and numeracy skills and a non-deliberative decision style, has screening experience, but did not experience a bad (i.e. unfavoured) screening test result yet. He does not have CRC diagnosed in his family, has a good health condition, did not visit the general practitioner (GP) or hospital in the last month, and is living together with a partner or family member. He is invited to join a CRC screening programme that has an effectiveness of $40 \%$, has a $25 \%$ risk of a falsenegative outcome, a screening frequency of every 2 years, a 2 -week waiting time for faecal immunochemical testing results and a 4-week waiting time for a colonoscopy follow-up test' towards population-based screening is important. Focusing on health promotion campaigns, tailored communication and/or awareness is a first next step. For example, by clarifying that an individual aged 55-75 years can reduce his/her risk of CRC-related mortality by joining the CRC screening programme, and that they do not have to pay for this screening test. Further research is warranted to investigate whether sending a more tailored letter to non-participants will reduce the negative attitude and as such the non-participation rate substantially.

Despite the fact that the present study used a mixed-methods approach that led to results with a high degree of validity, our study had several limitations. A potential weakness of the present study is that several attributes included in the DCE contained numbers and rates. This might have caused difficulties with completing the choice tasks; although $90.6 \%$ of the respondents reported that they did not find the DCE questions difficult. Second, the percentage of respondents (92.9\%) who stated they would participate in CRC screening was substantially higher than current Dutch CRC screening practice $(72.7 \%)$; therefore, we cannot exclude that selection bias may exist in our sample (noteworthy: another explanation might be that the intention to participate is not equal to participation in CRC screening). Finally, the current results could gain credibility if future research compares, for example using the approach of de Bekker-Grob et al. [21], the predicted CRC screening non-participation of respondents with their actual behaviour in CRC screening.

\section{Conclusions}

This study showed that although screening characteristics proved to influence non-participation in CRC screening, a respondent's characteristics had a much higher impact on CRC screening non-participation; particularly, the individual's general attitude towards CRC screening followed by whether the respondent had participated in a cancer 
screening programme before, the decision style and the educational level of the respondent. Policy makers and physicians can use these insights to improve and tailor their communication plans regarding CRC screening for unscreened individuals.

\section{Declarations}

Funding This study was funded by The Netherlands Organisation for Scientific Research (NWO-Talent-Scheme-Veni-Grant No. 45115-039). The funder had no role in the study design, the collection, analysis and interpretation of data, in the writing of the report or in the decision to submit the article for publication.

Conflict of interest Esther W. de Bekker-Grob, Bas Donkers, Jorien Veldwijk, Marcel F. Jonker, Sylvia Buis, Jan Huisman, and Patrick Bindels have no conflicts of interest that are directly relevant to the content of this article.

Ethics approval Approval for the study was obtained from the Medical Ethics Committee, Erasmus MC (MEC-2016-095).

Consent to participate All respondents gave their consent to participate in this study. The study was performed in accordance with the Declaration of Helsinki.

\section{Consent for publication Not applicable.}

Availability of data and material The dataset and the choice model syntax underpinning this research are available at https://www.eur.nl/ecmc.

Code availability Not applicable.

Author contributions Conceptualisation: EBG, BD, MJ, PB. Methodology: EBG, BD, JV, MJ, SB, JH, PB. Data collection: EBG, JV, SB, JH. Formal analysis: EBG, BD. Writing, original draft: EBG. Writing, review and editing: EBG, BD, JV, MJ, SB, JH, PB. Project administration: EBG, JV, SB, JH. Funding acquisition: EBG, BD, PB. Supervision: $\mathrm{EBG}, \mathrm{BD}, \mathrm{PB}$.

Open Access This article is licensed under a Creative Commons Attribution-NonCommercial 4.0 International License, which permits any non-commercial use, sharing, adaptation, distribution and reproduction in any medium or format, as long as you give appropriate credit to the original author(s) and the source, provide a link to the Creative Commons licence, and indicate if changes were made. The images or other third party material in this article are included in the article's Creative Commons licence, unless indicated otherwise in a credit line to the material. If material is not included in the article's Creative Commons licence and your intended use is not permitted by statutory regulation or exceeds the permitted use, you will need to obtain permission directly from the copyright holder. To view a copy of this licence, visit http://creativecommons.org/licenses/by-nc/4.0/.

\section{References}

1. Bray F, Ferlay J, Soerjomataram I, Siegel RL, Torre LA, Jemal A. Global cancer statistics 2018: GLOBOCAN estimates of incidence and mortality worldwide for 36 cancers in 185 countries. CA Cancer J Clin. 2018;68:394-424.
2. Mandel JS, Church TR, Bond JH, Ederer F, Geisser MS, Mongin SJ, et al. The effect of fecal occult-blood screening on the incidence of colorectal cancer. N Engl J Med. 2000;343:1603-7.

3. Shaukat A, Mongin SJ, Geisser MS, Lederle FA, Bond JH, Mandel JS, et al. Long-term mortality after screening for colorectal cancer. N Engl J Med. 2013;369:1106-14.

4. Bibbins-Domingo K, Grossman DC, Curry SJ, Davidson KW, Epling JW, García FAR, et al. Screening for colorectal cancer: US Preventive Services Task Force recommendation statement. JAMA. 2016;315:2564-75.

5. Zauber AG. The impact of screening on colorectal cancer mortality and incidence: has it really made a difference? Dig Dis Sci. 2015;60(3):681-91.

6. Levi Z, Birkenfeld S, Vilkin A, Bar-Chana M, Lifshitz I, Chared $\mathrm{M}$, et al. A higher detection rate for colorectal cancer and advanced adenomatous polyp for screening with immunochemical fecal occult blood test than guaiac fecal occult blood test, despite lower compliance rate: a prospective, controlled, feasibility study. Int J Cancer. 2011;128:2415-24.

7. Segnan N, Armaroli P, Bonelli L, Risio M, Sciallero S, Zappa $\mathrm{M}$, et al. Once-only sigmoidoscopy in colorectal cancer screening: follow-up findings of the italian randomized controlled trial: SCORE. J Natl Cancer Inst. 2011;103:1310-22.

8. Lieberman D, Moravec M, Holub J, Michaels L, Eisen G. Polyp size and advanced histology in patients undergoing colonoscopy screening: implications for CT colonography. Gastroenterology. 2008;135:1100-5.

9. van Rossum LG, van Rijn AF, Laheij RJ, van Oijen MG, Fockens $\mathrm{P}$, van Krieken $\mathrm{HH}$, et al. Random comparison of guaiac and immunochemical fecal occult blood tests for colorectal cancer in a screening population. Gastroenterology. 2008;135(1):82-90.

10. Atkin WS, Edwards R, Kralj-Hans I, Wooldrage K, Hart AR, Northover JM, et al. Once-only flexible sigmoidoscopy screening in prevention of colorectal cancer: a multicentre randomised controlled trial. Lancet. 2010;375:1624-33.

11. Hol L, De Bekker-Grob EW, Van Dam L, Donkers B, Kuipers EJ, Habbema JDF, et al. Preferences for colorectal cancer screening strategies: a discrete choice experiment. Br J Cancer. 2010;102:972-80.

12. Symonds EL, Pedersen S, Cole SR, Massolino J, Byrne D, Guy $\mathrm{J}$, et al. Improving participation in colorectal cancer screening: a randomised controlled trial of sequential offers of faecal then blood based non-invasive tests. Asian Pac J Cancer Prev. 2016;16:8455-60.

13. Soekhai V, de Bekker-Grob EW, Ellis AR, Vass CM. Discrete choice experiments in health economics: past, present and future. Pharmacoeconomics. 2019;37:201-26.

14. Benning TM, Dellaert BGC, Severens JL, Dirksen CD. The effect of presenting information about invasive follow-up testing on individuals' noninvasive colorectal cancer screening participation decision: results from a discrete choice experiment. Value Health. 2014;17(5):578-87.

15. Pignone MP, Crutchfield TM, Brown PM, Hawley ST, Laping $\mathrm{JL}$, Lewis CL, et al. Using a discrete choice experiment to inform the design of programs to promote colon cancer screening for vulnerable populations in North Carolina. BMC Health Serv Res. 2014;14(1): 1-9.

16. Mansfield C, Ekwueme DU, Tangka FKL, Brown DS, Smith JL, Guy GP, et al. Colorectal cancer screening: preferences, past behavior, and future intentions. Patient. 2018;11(6):599-611.

17. van Dam L, Hol L, de Bekker-Grob EW, Steyerberg EW, Kuipers EJ, Habbema JDF, et al. What determines individuals' preferences for colorectal cancer screening programmes? A discrete choice experiment. Eur J Cancer. 2010;102:972-80.

18. Kistler CE, Hess TM, Howard K, Pignone MP, Crutchfield TM, Hawley ST, et al. Older adults' preferences for colorectal 
cancer-screening test attributes and test choice. Patient Prefer Adher. 2015;9:1005.

19. Nayaradou M, Berchi C, Dejardin O, Launoy G. Eliciting population preferences for mass colorectal cancer screening organization. Med Decis Mak. 2010;30(2):224-33.

20. Martens CE, Crutchfield TM, Laping JL, Perreras L, Reuland DS, Cubillos L, et al. Why wait until our community gets cancer? Exploring CRC screening barriers and facilitators in the Spanish-speaking community in North Carolina. J Cancer Educ. 2016;31(4):652-9.

21. de Bekker-Grob EW, Donkers B, Bliemer MCJ, Veldwijk J, Swait JD. Can healthcare choice be predicted using stated preference data? Soc Sci Med. 2020;246:112736.

22. de Bekker-Grob EW, Donkers B, Jonker MF, Stolk EA. Sample size requirements for discrete-choice experiments in healthcare: a practical guide. Patient. 2015;8(5):373-84.

23. Ryan M. Discrete choice experiments in health care. BMJ. 2004;328(7436):360-1.

24. Hensher D, Rose J, Greene W. Applied choice analysis. 2nd ed. Cambridge: Cambridge University Press; 2015.

25. Hiligsmann M, van Durme C, Geusens P, Dellaert BGC, Dirksen $\mathrm{CD}$, van der Weijden $\mathrm{T}$, et al. Nominal group technique to select attributes for discrete choice experiments: an example for drug treatment choice in osteoporosis. Patient Prefer Adher. 2013;7:133.

26. Schreuders EH, Ruco A, Rabeneck L, Schoen RE, Sung JJY, Young GP, et al. Colorectal cancer screening: a global overview of existing programmes. Gut. 2015;64:1637-49.

27. Lansdorp-Vogelaar I, Knudsen AB, Brenner H. Cost-effectiveness of colorectal cancer screening. Epidemiol Rev. 2011;33:88-100.

28. Quintero E, Castells A, Bujanda L, Cubiella J, Salas D, Lanas Á, et al. Colonoscopy versus fecal immunochemical testing in colorectal-cancer screening. N Engl J Med. 2012;366(8):697-706.

29. Jonker MF, Donkers B, de Bekker-Grob E, Stolk EA. Attribute level overlap (and color coding) can reduce task complexity, improve choice consistency, and decrease the dropout rate in discrete choice experiments. Health Econ. 2019;28:350-63.

30. Sándor Z, Wedel M. Heterogeneous conjoint choice designs. J Mark Res. 2005;42(2):210-8.

31. Glanz K, Rimer BK, Viswanath K. Health behavior: theory, research, and practice. San Francisco: Jossey-Bass; 2015.

32. Pachur T, Spaar M. Domain-specific preferences for intuition and deliberation in decision making. J Appl Res Mem Cogn. 2015;4:303-11.
33. Ishikawa H, Takeuchi T, Yano E. Measuring functional, communicative, and critical health literacy among diabetic patients. Diabetes Care. 2008;31:874-9.

34. van der Vaart R, Drossaert CHC, Taal E, ten Klooster PM, Hilderink-Koertshuis RTE, Klaase JM, et al. Validation of the Dutch functional, communicative and critical health literacy scales. Patient Educ Couns. 2012;89:82-8.

35. Fagerlin A, Zikmund-Fisher BJ, Ubel PA, Jankovic A, Derry HA, Smith DM. Measuring numeracy without a math test: development of the subjective numeracy scale. Med Decis Mak. 2007;27:672-80.

36. Zikmund-Fisher BJ, Smith DM, Ubel PA, Fagerlin A. Validation of the subjective numeracy scale: effects of low numeracy on comprehension of risk communications and utility elicitations. Med Decis Mak. 2007;27:663-71.

37. de Bekker-Grob E, Swait J, Kassahun H, Bliemer M, Jonker M, Veldwijk J, et al. Are healthcare choices predictable? The impact of discrete choice experiment designs and models. Value Health. 2019;22:1050-62.

38. Hauber AB, González JM, Groothuis-Oudshoorn CGM, Prior T, Marshall DA, Cunningham C, et al. Statistical methods for the analysis of discrete choice experiments: a report of the ISPOR Conjoint Analysis Good Research Practices Task Force. Value Health. 2016;19(4):300-15.

39. Lancsar E, Fiebig DG, Hole AR. Discrete choice experiments: a guide to model specification, estimation and software. Pharmacoeconomics. 2017;35(7):697-716.

40. Bierlaire M. Estimating choice models with latent variables with PythonBiogeme, technical report TRANSP-OR 160628. Transport and Mobility Laboratory, ENAC, EPFL; 2016.

41. Train K. Discrete choice methods with simulation. Cambridge: Cambridge University Press; 2003.

42. Revelt D, Train K. Customer-specific taste parameters and mixed logit: households' choice of electricity supplier. 2000. https:// cloudfront.escholarship.org/dist/prd/content/qt1900p96t/qt190 0p96t.pdf. Accessed 25 Oct 2020.

43. Hess S. Conditional parameter estimates from mixed logit models: distributional assumptions and a free software tool. J Choice Model. 2010;3(2):134-52.

44. Dellaert BGC, Donkers B, Van Soest A. Complexity effects in choice experiment-based models. J Mark Res. 2012;49:424-34.

45. Louviere JJ, Islam T, Wasi N, Street D, Burgess L. Designing discrete choice experiments: do optimal designs come at a price? J Consum Res. 2008;35:360-75. 